Canadian

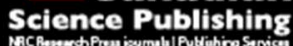

Applied Physiology, Nutrition, and Metabolism Physiologie appliquée, nutrition et métabolisme

\title{
Muscular contraction frequency does not affect plasma homocysteine concentration in response to energy expenditure and intensity matched acute exercise in sedentary males
}

\begin{tabular}{|c|c|}
\hline Journal: & Applied Physiology, Nutrition, and Metabolism \\
\hline Manuscript ID & apnm-2017-0265.R1 \\
\hline Manuscript Type: & Article \\
\hline Date Submitted by the Author: & 04-Aug-2017 \\
\hline Complete List of Authors: & $\begin{array}{l}\text { Úbeda, Natalia; CEU San Pablo University, Pharmaceutical Sciences and } \\
\text { Health } \\
\text { Carson, Brian; Physical Education and Sport Sciences, University of } \\
\text { Limerick, Ireland } \\
\text { García-González, Ángela; CEU San Pablo University, Pharmaceutical } \\
\text { Sciences and Health } \\
\text { Aguilar-Ros, Antonio; CEU San Pablo University, Pharmaceutical Sciences } \\
\text { and Health } \\
\text { Díaz-Martínez, Ángel Enrique; Sports Medicine Center, Clinical Laboratory. } \\
\text { Higher Council for Sports, Madrid, Spain. } \\
\text { Venta, Rafael; Hospital San Agustín, Service of Biochemistry } \\
\text { Terrados, Nicolás; Regional Centre of Sport Medicine, Fundación Deportiva } \\
\text { Municipal, ; University of Oviedo, Department of Functional Biology } \\
\text { O'Gorman, Donal; Dublin City University } \\
\text { Iglesias-Gutiérrez, Eduardo; UNIVERSIDAD DE OVIEDO, FACULTAD DE } \\
\text { MEDICINA, }\end{array}$ \\
\hline \multicolumn{2}{|l|}{$\begin{array}{r}\text { Is the invited manuscript for } \\
\text { consideration in a Special } \\
\text { Issue? : }\end{array}$} \\
\hline Keyword: & $\begin{array}{l}\text { Homocysteine kinetics, exercise prescription < exercise, frequency of } \\
\text { contraction }\end{array}$ \\
\hline
\end{tabular}

\section{SCHOLARONE" \\ Manuscripts}


Title: Muscular contraction frequency does not affect plasma homocysteine concentration in response to energy expenditure and intensity matched acute exercise in sedentary males.

Running title: Homocysteine and muscular contraction frequency.

Authors: Natalia Úbeda ${ }^{1}$, Brian P. Carson $^{2}$, Ángela García-González ${ }^{1}$, Antonio Aguilar-Ros ${ }^{1}$, Ángel Enrique Díaz-Martínez ${ }^{3}$, Rafael Venta ${ }^{4,5}$, Nicolás Terrados ${ }^{6,7}$, Donal J. O’Gorman ${ }^{8,9}$, Eduardo Iglesias-Gutiérrez ${ }^{6}$.

\section{Affiliations:}

1 Department of Pharmaceutical Sciences and Health. Universidad San Pablo-CEU, CEU Universities. Madrid, Spain.

2 Physical Education and Sport Sciences, University of Limerick, Ireland.

3 Sports Medicine Center, Clinical Laboratory. Higher Council for Sports, Madrid, Spain.

4 Service of Biochemistry. Hospital San Agustín, Avilés, Spain.

5 Department of Biochemistry and Molecular Biology, University of Oviedo, Oviedo, Spain.

6 Department of Functional Biology. University of Oviedo, Oviedo, Spain.

7 Regional Centre of Sport Medicine. Fundación Deportiva Municipal, Avilés, Spain.

8 National Institute for Cellular Biotechnology, Dublin City University, Dublin, Ireland

$93 \mathrm{U}$ Diabetes Consortium and School of Health and Human Performance, Dublin City

University, Dublin, Ireland 


\section{Corresponding author:}

Natalia Úbeda Martín

Department of Pharmaceutical Sciences and Health. Universidad San Pablo-CEU, CEU

Universities, Madrid, Spain.

Ctra. Boadilla del Monte km 5,3 (Urbanización Montepríncipe), 28668 Boadilla del Monte, Madrid, Spain.

Phone number: +343724006

Fax number: +343510475

E-mail: nubeda@ceu.es 


\begin{abstract}
Acute exercise seems to increase total plasma homocysteine (tHcy). That is related to cardiovascular risk, therefore it is important to understand the determinants of its response to all types of exercise. The aim of this study was to examine the impact of cycling at two different rates of muscle contraction on the complete tHcy kinetics. Eight young sedentary males were required to complete two isocaloric $(400 \mathrm{kcal})$ acute exercise trials at $50 \% \mathrm{VO}_{2}$ peak on separate occasions at 50 or 80 revolutions per minute (rpm). Blood samples were drawn at different points before (pre4 and pre0 h), during (exer10, exer20, exer30, exer45, and exer60 min), and after exercise (post0 and post19 h). Dietary and lifestyle factors were controlled during the research. Maximum tHcy occurred during exercise, for both conditions (50 rpm: $11.4 \pm 2.7 \mu \mathrm{mol} / \mathrm{L} ; 80 \mathrm{rpm}: 10.8$ $\pm 3.2 \mu \mathrm{mol} / \mathrm{L}$ ). From this point onwards tHcy declined until the cessation of exercise and continued descending below pre exercise values at $19 \mathrm{~h}$ post exercise $(p<0.05)$. No hyperhomocysteinemia were observed at any sampling point in both trials. In conclusion, the different muscular contraction frequency during exercise has no impact on tHcy during an acute bout of exercise in sedentary individuals, when at least 400 kcal are spent during exercise and the nutritional status for folate, $B_{12}$, and $B_{6}$ is adequate. This information is relevant to further inform healthy exercise prescription, not only in terms of duration and intensity of exercise, but also taking into account frequency of contraction.
\end{abstract}

Keywords: Homocysteine kinetics; Exercise prescription; frequency of contraction. 


\section{Introduction}

Homocysteine (tHcy) is a non-protein sulphur-containing amino acid whose elevated plasma concentration constitutes an independent risk of cardiovascular disease (CVD), via endothelial dysfunction, oxidative stress mechanisms and inflammatory vascular processes (Mangoni and Woodman 2011; Moat 2008; Refsum et al. 1998; Veeranna et al. 2011). tHcy is strongly influenced by genetic and lifestyle factors such as diet, especially vitamins $B_{12}, B_{6}$ and folic acid (Chrysohoou et al. 2004). However, the impact of exercise on tHcy remains unclear. A recent review (Maroto-Sánchez et al. 2016) identifies that acute exercise induces increases in tHcy. However, no consensus exists regarding chronic exercise due to a large variety of exercise interventions, with different intensities, duration and mode of exercise. Deminice et al. (2016), in a metaanalysis, also reported that acute exercise increases plasma Hcy concentration independent of duration or intensity of the exercise performed and, at the same time, regular resistance training can decrease plasma Hcy concentration, though this was not observed after aerobic exercise training.

We have previously reported that acute exercise at high and low intensity in healthy sedentary individuals causes a transient increase of plasma tHcy proportional to the intensity of exercise, but not hyperhomocysteinemia (Iglesias-Gutiérrez et al. 2012). According to the American Heart Association (AHA) advisory statement (Malinow et al. 1999) normal homocysteine concentrations range from 5-15 $\mu \mathrm{mol} / \mathrm{L}$. Deminice et al. (2016) also provided evidence that the elevation of tHcy as a consequence of an acute bout of exercise does not cause hyperhomocysteinemia. However, we have previously shown a 26\% increase in tHcy (Iglesias-Gutiérrez et al. 2012), which could have physiological or clinical relevance. 
The underlying mechanism remains unclear, although our previous data suggest that it could be related to increased energy expenditure (Iglesias-Gutiérrez et al. 2012), since the maximal tHcy concentration occurred during exercise. At the same time, we have also showed that it could be related to changes in renal function in response to exercise (Venta et al. 2009). In this sense, increased tHcy is not as a direct result of exercise, but could be an indirect consequence of the whole body homeostatic perturbation in response to exercise.

Plasma concentration of homocysteine is related to cardiovascular risk and exercise is one of the interventions most widely recommended to reduce CVD risk. On the other hand, an important proportion of European citizens (59\%) never exercises or seldom do so (Eurobarometer, 2014). Therefore, it is important to understand the determinants of the tHcy response to exercise with the aim of optimizing exercise prescription for the prevention of CVD, especially in sedentary people. These recommendations should not be expressed only in terms of duration and intensity of exercise; since some authors have described that the frequency of contraction or the velocity of shortening of skeletal muscle can also affect energy expenditure and substrate utilization (Kang et al. 2004) and, in consequence, could also influence the plasma concentration of tHcy.

Therefore, the aim of this study was to assess the effect of frequency of muscle contraction in tHcy kinetics. In this sense, we examined the impact of cycling at two different rates/frequencies of muscle contraction (50 and $80 \mathrm{rpm}$ ), on the complete tHcy kinetics in sedentary individuals, when dietary and lifestyle factors were controlled.

\section{Subjects and methods}

\section{Ethics statement}


All experimental procedures were approved by the Dublin City University Research Ethics Committee in accordance with the Declaration of Helsinki. All participants gave written informed consent.

\section{Subjects}

Participants were recruited using flyers posted on campus and e-mail sent to the student and staff mailing lists. Prior to participation, each volunteer underwent a thorough medical screening to determine eligibility. Eight young males (19-32 yr) who were healthy, and had been physically inactive for at least 6 months, took part in the study.

\section{Anthropometry and aerobic capacity assessment}

On their first visit, the participants had their body composition assessed and their peak oxygen uptake $\left(\mathrm{VO}_{2 \text { peak }}\right)$ determined at the Metabolic Physiology Research Unit.

Height and body mass (BM) were measured using a combined medical scale (model 778, Seca Ltd, Hamburgh, Germany; precision $0.1 \mathrm{~cm}$ for height and $0.1 \mathrm{~kg}$ for weight) and the body mass index (BMI) was calculated. Body density was calculated by the method of Jackson and Pollock (1978), based on the sum of seven skinfolds (triceps, subscapular, mid-axillary, pectoral, suprailiac, abdominal, thigh) measured with Harpenden skinfold calipers (Holtain Ltd., Crosswell, Crymych, Pembrokeshire, UK). Percentage body fat $(\% \mathrm{BF})$ was calculated using the equation of Siri (1961). $\mathrm{VO}_{2 \text { peak }}$ was determined by indirect calorimetry (Vmax 29C, SensorMedics, Yorba Linda, CA, USA) using an incremental protocol on an electronically braked stationary cycle ergometer (Ergoline 900, SensorMedics). Subjects began cycling at $100 \mathrm{~W}$ for five minutes to warm-up and the power output was increased by $50 \mathrm{~W}$ every two minutes thereafter until volitional fatigue. Oxygen uptake was considered to have peaked if two of the following criteria were met: (i) a levelling off of $\mathrm{VO}_{2}$ with increasing power output (increase of less than $2 \mathrm{~mL} \cdot \mathrm{kg}^{-1} \cdot \mathrm{min}^{-1}$ ), (ii) a HR within 10 beats of the age 
predicted $\mathrm{HR}_{\max }(220 \mathrm{bpm}$ - age in years), (iii) a RER greater than 1.10. Between four and seven days later, each participant returned to the laboratory to perform sub-maximal exercise to verify the power outputs required to elicit $50 \% \mathrm{VO}_{2}$ peak. The power output required to elicit a given percentage of $\mathrm{VO}_{2}$ peak was estimated based on the linear relationship between oxygen uptake (y-axis) and power output (x-axis). For a given percentage of $\mathrm{VO}_{2}$ peak, the corresponding power output was estimated by solving for $\mathrm{x}$ using the linear function, $\mathrm{y}=\mathrm{mx}+\mathrm{c}$, where $\mathrm{y}$ is $\mathrm{VO}_{2}, \mathrm{x}$ is power output, $\mathrm{m}$ is the slope of the relationship between $\mathrm{VO}_{2}$ and power output and $\mathrm{c}$ is the $\mathrm{y}$-axis intercept. Subjects cycled for $10 \mathrm{~min}$ at a number of different power outputs, starting at $15 \mathrm{~W}$ below the predicted power output and adjusted thereafter until the correct percentage of $\mathrm{VO}_{2}$ peak was maintained in steady state. This trial took approximately 30-40 minutes.

\section{Experimental design}

In a randomized crossover design (Figure 1), subjects were required to exercise at the workload that corresponds to $50 \%$ of their VO2peak (determined from the maximal test) at either 50 or 80 revolutions per minute (rpm) on an electronically braked stationary cycle ergometer (Ergoline 900,SensorMedics). Each exercise bout was separated by 7 days and required the participants to expend $400 \mathrm{kcal}$, determined by indirect calorimetry monitored on a minute-by-minute basis and calculated using the equations of Weir et al (1949). The duration of both exercise trials to expend $400 \mathrm{kcal}$ were not significantly different (50rpm: $58.5 \pm 3.1 \mathrm{~min}$; 80rpm: $52.6 \pm 3.0 \mathrm{~min}$ )

\section{Dietary control}

Participants were asked to keep a one-day food diary on the day prior to the first experimental trial and asked to repeat the content and pattern of dietary intake on the day preceding the second experimental trial. They were asked to abstain from caffeine and alcohol consumption for $24 \mathrm{~h}$ prior to testing, and none of them reported the use of 
vitamin supplements. Dietary records were analyzed using a nutrient analysis program (WISP, Tinuviel Software, UK) (Food Standards Agency 2002).

The dietary intake during each experimental trial was standardized in terms of food type and macronutrient composition, and individualized for each participant in terms of total energy content. The individual energy requirements were calculated using the HarrisBenedict equation (Harris and Benedict 1919), multiplied by a physical activity factor (1.4), and with $400 \mathrm{kcal}$ added to account for the exercise trial (Durnin 1996). Three meals, each with $30 \%$ of predicted total energy expenditure, were provided, with the remaining $10 \%$ energy supplied with an evening snack. In accordance with current Recommended Dietary Allowances (RDA) (FSAI 1999) and Acceptable Macronutrient Distribution Range (AMDR) (Food and Nutrition Board 2005), these meals were designed to provide $45-65 \%, 20-35 \%$, and $10-35 \%$ of total energy intake from carbohydrate $(\mathrm{CHO})$, fat and protein sources, respectively, as well as an adequate intake of folate, vitamin B12, and vitamin B6.

\section{Experimental protocol}

For the experimental trials subjects reported to the laboratory after an overnight fast and had a blood sample taken (pre4 point). Subjects then consumed a standardized breakfast and remained in the laboratory for $4 \mathrm{~h}$, at which point they started the exercise bout. Immediately before exercise another blood sample was taken (pre0). Participants then began cycling on a stationary ergometer (cadence at 50 or $80 \mathrm{rpm}$ ) and continued until $400 \mathrm{kcal}$ were expended. If participants deviated from the designated cadence by more than 5RPM they were encouraged by the experimenters to adopt the correct cadence, which was easily accommodated at sub-maximal exercise. During exercise blood samples were drawn every 10-15 min (exer10, exer20, and exer30...) until exhaustion, via catheter placed in the antecubital vein. Sampling points were the same for both 
exercise trials, though a smaller number of subjects reached exer50 $(n=5$ for $50 \mathrm{rpm} ; \mathrm{n}=2$ for80rpm) and exer60 ( $\mathrm{n}=2$ for $50 \mathrm{rpm}$; $\mathrm{n}=1$ for $80 \mathrm{rpm}$ ) as they had already expended $400 \mathrm{kcal}$. The total volume of blood taken during the trial was less than $40 \mathrm{ml}$. Another blood sample was drawn immediately at the end of exercise (post0). After 3 hours, subjects were provided with a standard meal, after which they were free to leave the laboratory. Another meal and snack were provided to eat later that evening, and water intake was permitted to their satisfaction. No other food or beverages were allowed. The following morning subjects returned to the laboratory at the same time as the previous day, after an overnight fast, for a final blood sample taken at $19 \mathrm{~h}$ after the cessation of exercise (post19).

Blood samples (4 ml) were collected in vacutainers (No Additive (Z), Becton Dickinson, Franklin Lakes, NJ), kept at room temperature for $20 \mathrm{~min}$, and then centrifuged at $3000 \mathrm{rpm}$ for $15 \mathrm{~min}$ at $4^{\circ} \mathrm{C}$. The serum was stored at $-80^{\circ} \mathrm{C}$ for later analysis.

\section{Biochemical determinations}

tHcy were determined by HPLC using a commercially available kit (Chromsystems Instruments \& Chemicals GmbH, Munich, Germany) and fluorescent detection, where a derivatization process of the sample takes place. Once the sample is prepared, $50 \mu 1$ are injected into the HPLC and fluorescence is measured at $385 \mathrm{~nm}$ excitation and $515 \mathrm{~nm}$ emission. Folate and vitamin $B_{12}$ serum concentrations were measured using an ELECSYS system (Roche Diagnostics GmbH, D-68298 Mannheim, Germany) based on an electrochemiluminescence immunoassay (ECLIA).

\section{Kinetic parameters}

Area under the curve (AUC), maximum concentration (Cmax) and time to maximum concentration (Tmax), of tHcy, folate and vitamin B12 in serum were calculated by a 
noncompartmental method, assuming apparent first-order kinetic in the terminal phase of elimination, evidenced by linearity of a semi-log plot. Pharmacokinetic parameters have been obtained by means of an Excel spreadshet (Aguilar-Ros et al. 2014).

\section{Statistical analysis}

Normality of variables was tested using Shapiro Wilk's test. In light of the results obtained, descriptive values are presented as mean \pm standard deviation or median (interquartile range).

T-Student test for related samples was performed to analyze differences between contraction frequencies at the same sampling points, as well as between sampling points at the same contraction frequencies, for the variables considered. In order to check the relationship among the different variables at each time point, a full correlation analysis was made by using Pearson correlation coefficient.

The level of significance was set at $\mathrm{p}<0.05$ for all analyses; Descriptive and analytical statistical analyses were performed using IBM ${ }^{\circledR}$ SPSS ${ }^{\circledR}$ Statistics, version 20.0 (Somers, NY).

\section{Results}

Anthropometric characteristics (height, body mass, BMI, \% body fat) and aerobic capacity $\left(\mathrm{VO}_{2 \text { peak }}\right)$ of volunteers are presented in Table 1 , showing a profile of young, non-obese, sedentary males, with low aerobic capacity.

The graphic representation of the serum clearance kinetics of tHcy is shown in Figure 2. No statistical differences in tHcy were found at baseline (pre4 and pre0) between 50 rpm and $80 \mathrm{rpm}$. tHcy response to 50 and $80 \mathrm{rpm}$ was similar and no statistically significant differences were observed at any sampling point between trials. An increase in tHcy was observed in both cases, reaching Cmax $(11.4 \pm 2.7 \mu \mathrm{mol} / \mathrm{L}$ for $50 \mathrm{rpm}$ and 
$10.8 \pm 3.2 \mu \mathrm{mol} / \mathrm{L}$ for $80 \mathrm{rpm}$ ) after 23 and $14 \mathrm{~min}$, respectively. This represents a $16.3 \%$ and $10.2 \%$ increase. No statistically significant differences were found for Cmax and Tmax at 50 vs. $80 \mathrm{rpm}$. From this point onwards tHcy progressively decreased and continued after the cessation of exercise. At post19, tHcy was not different from pre4 but was significant lower than pre 0 value in $80 \mathrm{rpm}$ exercise. At $50 \mathrm{rpm}$ of exercise, tHcy significantly decreased in post 19 point with respect to pre4 point. Surprisingly, the increase observed in tHcy during $50 \mathrm{rpm}$ was slightly higher. No values of hyperhomocysteinemia (tHcy > $15 \mu \mathrm{mol} / \mathrm{L})$ (Selhub 1999; Welch and Loscalzo 1998) were observed at any sampling point in both exercise trials.

Table 2 shows data relative to area under curve (AUC) between 0 and 30 minutes of exercise (coincident duration time in all exercises) together with Cmax and Tmax. Table 2 also shows differences between the tHcy concentration at points post0-pre0 (representative of an acute bout of exercise) and difference between points post19-pre4 (representative of recovery post exercise). There were no between trial differences in these parameters except a significantly lower tHcy at 80rpm at post0-pre0.

Table 3 shows the serum concentration of folate and vitamin B12 at every sample point. Serum folate concentration increased after the exercise (post0 and post19) with respect to the other points and this change is significant in the 80rpm exercise. We also observed a higher Cmax and Tmax at $80 \mathrm{rpm}$ exercise compared with $50 \mathrm{rpm}$ exercise (Table 4). There were significant differences between trials at pre4 and post 19 for folate and at post 19 for vitamin $\mathrm{B}_{12}$. In both vitamins the higher concentration was found in the $80 \mathrm{rpm}$ exercise. The serum concentration of the vitamins were adequate at every sampling point (folate: $>3.4 \mathrm{nmol} / \mathrm{L}(>1.5 \mathrm{ng} / \mathrm{ml}$ ); vitamin $\mathrm{B} 12:>120 \mathrm{pmol} / \mathrm{L}$ (>162 pg/ml) (Joubert and Manore 2008; Brito et al. 2012). 
The correlation analysis among the serum concentration of tHcy and the different vitamins analyzed showed a large variability and no relevant tendency was observed. Energy, macronutrient, folate, vitamin $\mathrm{B}_{12}$, and vitamin $\mathrm{B}_{6}$ intake during the experimental trials, compared to the RDA and AMDR, are shown in Table 5. The dietary intake of the volunteers was in accordance with the proposed targets for energy, macronutrients, and vitamins.

\section{Discussion}

We examined the impact of exercise at two different rates of muscle contraction (high and low cycle cadence: 80 and $50 \mathrm{rpm}$ ) on the complete tHcy kinetics in an energy expenditure and intensity-matched experiment, carried out in sedentary individuals with low aerobic capacity, controlling dietary and lifestyle factors.

thcy response to cycling at $50 \% \mathrm{VO}_{2}$ peak at 50 and $80 \mathrm{rpm}$ was similar and no statistically significant differences were observed at any sampling point between trials. Therefore, no effect of frequency of contraction on tHcy kinetics was observed when the exercise was carried out at the same intensity and energy expenditure. An increase in tHcy during exercise was observed in both trials, reaching Cmax during exercise, although hyperhomocysteinemia was not observed at any time point. tHcy showed a modest reduction $19 \mathrm{~h}$ post exercise in both conditions suggesting a positive effect of exercise in the recovery period.

Souza-Silva and Gonçalves da Mota (2014) in a recent revision asserted that it would be prudent to discern the types of exercise that reduce homocysteine levels and therefore potentially reduce the risk of blood vessel damage. According to these authors, and others (Maroto-Sánchez et al. 2016), homocysteine was lower in patients with the greatest amount of daily physical activity. 
Several studies have reported increased homocysteine levels immediately after an acute bout of exercise. Deminice et al. (2016), in a recent meta-analysis, showed that this elevation is independent of exercise intensity, although changes appear to be more sensitive to long-term exercise of low to moderate intensity than short-term exercise of high intensity, i. e. increased homocysteine induced by exercise was significantly associated with volume of exercise. On the other hand, the aerobic exercise training analysis did not demonstrate a significant impact on homocysteine levels in the blood, whereas resistance training was found to decrease plasma tHcy.

Taking together our results and those of other authors aforementioned, we could deduce that the type and volume of exercise could influence the concentration of tHcy rather than the intensity or frequency of contraction.

Kinetic studies that include multiple sampling points both pre, during and post exercise regarding Hcy metabolism such as those reported here are recommended in order to clarify the mechanisms through which tHcy is impacted by exercise (Deminice et al. 2016). Our studies are unique in providing a complete Hcy kinetics perspective pre, during and post exercise. Our previous study showed a transitory increase in tHcy levels during exercise and a recovery of basal levels 19 hours after the exercise (IglesiasGutiérrez et al. 2012). Also, in the present study, tHcy was significantly lower at post 19 compared with pre4, indicating a recovery of tHcy within 19 hours of exercise. Understanding this response could be relevant in terms of further informing healthy exercise prescription, since this could mean that acute exercise, even performed by sedentary people, would not have the deleterious effects previously reported by several authors. This could also elucidate the mechanism through which reduced circulating Hcy is observed in those who are more physically active (Maroto-Sánchez et al. 2016). Therefore, the 24 hour kinetic profile investigated in our studies indicate a post exercise 
recovery in response to exercise of varying intensity and contraction frequency, with no negative effects on tHcy as independent risk factor for CVD. Deminice et al. (2016) support the view that increased tHcy during acute exercise might not be deemed a risk factor of cardiovascular events mediated by hyperhomocysteinemia. Le Goff et al. (2011) also informed that isokinetic exercise leads to the release of CVD biomarkers in the blood, but these do not exceed healthy reference values in sedentary subjects. Maximal concentric isokinetic exercise does not, therefore, lead to an increased risk of cardiovascular pathologies. Understanding the mechanisms of changes in these markers after one session of exercise is essential for specifying the exact cardio protective benefits of long term exercise (Markovitcch et al. 2008).

Folates and other B-vitamins, are essential to maintain safe homocysteine concentrations. An inverse relationship between tHcy and serum folate has been described, but only when the nutritional status for folic acid was adequate (GonzálezGonzález et al. 2005; Úbeda et al. 2011; Varela-Moreiras et al. 2007). Despite the optimal folate and vitamin $\mathrm{B}_{12}$ status of the volunteers that took part in our study, an increase in tHcy was observed during exercise. So, in light of our results, adequate folate and vitamin $\mathrm{B}_{12}$ intake could be particularly important for people that are less active, and who are exposed to transient increases in tHcy during exercise. This may be particularly pertinent for exercise at high cycling cadence, since we observed a significant increase in both vitamins immediately post- and 19 hours after exercise, indicating the high demand of these vitamins in this type of exercise.

Consequently, acute exercise, even of high intensity and high cycling cadence, has no negative effect on tHcy as an independent risk factor for CVD, when at least $400 \mathrm{kcal}$ are spent during exercise and the nutritional status for folates and vitamin $\mathrm{B}_{12}$ was adequate. These results inform the response of a risk factor for CVD to acute exercise in 
sedentary people and are relevant for public health recommendations and exercise prescription. Therefore, attention should be given to identifying the optimal combination of exercise intensity, type and volume needed to induce favorable adaptations in the most time efficient manner, considering that a single bout of acute exercise does not increase tHcy over cardiovascular risk values in sedentary people.

\section{Strengths and limitations}

The strengths of our study are the meticulous experimental protocol and the strict control and characterization of the volunteers, particularly of their dietary intake. Furthermore, sequential blood samples were collected during exercise, which provides a unique perspective of the kinetics of the parameters assessed in response to acute exercise. Finally, the randomized crossover design of this study enabled each subject to be his own control, reducing the variability and strengthening the statistical analysis.

Some limitations should also be noted. First, the strict inclusion criteria and the invasive nature of the study, limited the possibility of recruiting a larger number of subjects. However, as mentioned before, in the repeated-measures design of the present study, the same 8 subjects participated in two different acute exercise bouts (at 50 and $80 \mathrm{rpm}$ ) and provided at least 7 samples before, during and after each event, which led us to analyse more than 100 samples. Second, generalization of results is limited by the characteristics of the study subjects: young, physically inactive males, without cardiovascular risk factors. Thus, the conclusions have been written accordingly. Finally, although the aim of this study focused on tHcy, the analysis of other cardiometabolic risk factors could have also been of interest. However, considering the plethora of cardiometabolic risk factors, the parameters selected could be biased by subjective selection. Furthermore, considering that each parameter could show different 
plasma appearance-clearance kinetics, the experimental protocol designed could not account for all this heterogeneous response.

Funding sources: This work was supported by grants from the Irish Research Council for Science, Engineering and Technolog to DO'G; the Higher Council for Sports of the Government of Spain (03/UPR10/08 and 002/UPR10/12 to NÚ), San PabloCEUUniversity (USP-BSCH-PPC11/09 to EI-G and NÚ) and by the Ministerio de Economía y Competitividad (DEP2012-39262 to EI-G). The funders had no role in study design, data collection and analysis, decision to publish, or preparation of the manuscript.

Conflicts of Interest: The authors have declared that no competing interests exist.

Acknowledgements: The study was designed by BC, DO'G, NÚ and EI-G; data were collected and analyzed by BC, DO'G, NÚ, AA-R, ÁED-M, RV, and NT; data was interpreted by ÁG, AA-R, EI-G and NÚ; manuscript preparation were undertaken by NÚ, ÁG and EI-G. All authors approved the final version of the paper. We would like to thank Alfredo Sánchez-Alberca for his help on the making the figure.

\section{References:}

Aguilar Ros, A., Caamaño, M., Martín, F.R., and Montejo M.C. 2014. Excel worksheet for pharmacokinetic calculations-user guide. In: Biofarmacia y Farmacocinética. Ejercicios y problemas resueltos. Ed. Elsevier. Barcelona. Spain. URL: http://www.studentconsult.es/bookportal/biofarmacia-farmacocinetica-2/aguilar/anexoiii-instrucciones/9788490222607/500/5064.html 
Bellamy, M.F., McDowell, I.F., Ramsey, M.W., Brownlee M., Bones, C., Newcombe R.G., et al. 1998. Hyperhomocysteinemia after an oral methionine load acutely impairs endothelial function in healthy adults. Circulation, 98: 1848-1852.

Brito, A., Hertrampf, E., Olivares, M., Gaitán, D., Sánchez, H., Allen, L.H., et al. 2012. Folatos y vitamina B12 en la salud humana. Rev. Med. Chile. 14: 1464-1475.

Chrysohoou, C., Panagiotakos, D.B., Pitsavos, C., Zeimbekis, A., Zampelas, A., Papademetriou, L., et al. 2004. The associations between smoking, physical activity, dietary habits and plasma homocysteine levels in cardiovascular disease-free people: the 'ATTICA' study. Vasc. Med. 9: 117-123.

Deminice, R., Ribeiro, D.F., and Frajacomo F.T. 2016. The Effects of Acute Exercise and Exercise Training on Plasma Homocysteine: A Meta-Analysis. PLoS One, 17: 11(3):e0151653.

Durnin, J.V. 1996. Energy requirements: general principles. Eur. J. Clin. Nutr., 50 (Suppl 1): S2-9; discussion 9-10.

Eurobarometer (2014) Sport and physical activity. Brussels: TNS Opinion \& Social.

e Silva Ade, S., and da Mota, M.P. 2014. Effects of physical activity and training programs on plasma homocysteine levels: a systematic review. Amino Acids, 46(8): 1795-1804. 
Food and Nutrition Board. Institute of Medicine of the National Academies. 2005.

Dietary Reference Intakes for Energy, Carbohydrate, Fiber, Fat, Fatty Acids, Cholesterol, Protein, and Amino Acids. Washington D.C.: The National Academies Press.

Food Safety Authority of Ireland (FSAI). 1999. Recommended Dietary Allowances for Ireland. Dublin.

Food Standards Agency. 2002. McCance and Widdowson's The Composition of Foods. London: RSC Publishing.

Gelecek, N., Teoman, N., Ozdirenc, M., Pinar, L., Akan, P., Bediz, C., and et al. 2007. Influences of acute and chronic aerobic exercise on the plasma homocysteine level. Ann. Nutr. Metab. 51: 53-58.

González González, M.P., Moreno Almazán, L., Cornide, M., García Rico, E., AlonsoAperte, E., and Varela-Moreiras, G. 2005. Homocisteína, Folatos y Vitamina B12 y Cáncer Colorrectal. Estudio Caso Control en Humanos. Nutr. Hosp. XX, 28-29.

Harris, J.A., and Benedict, F.G. 1919. A biometric study of basal metabolism in man. Washington DC: Carnagie Institution of Washington.

Iglesias-Gutiérrez E., Egan B., Díaz-Martínez A.E., Peñalvo J.L., González-Medina A., Martínez-Camblor P., et al. 2012. Transient Increase in Homocysteine but Not 
Hyperhomocysteinemia during Acute Exercise at Different Intensities in Sedentary Individuals. PLos One, 12: e51185.

Jackson, A.S., and Pollock, M.L. 1978. Generalized equations for predicting body density of men. Br. J. Nutr. 40: 497-504.

Joubert L.M., and Manore M.M. 2008. The role of physical activity level and B-vitamin status on blood homocysteine levels. Med. Sci. Sports Exerc., 40: 1923-1931.

Joubert, L.M. Exercise, nutrition and homocysteine. Thesis for the degree of Doctor of Philosophy. Oregon State University. 2008.

Kang, J., Hoffman, J.R., Wendell, M., Walker, H., and Hebert, M. 2004. Effect of contraction frequency on energy expenditure and substrate utilisation during upper and lower body exercise. Br. J. Sports. Med., 38: 31-35.

Le Goff, C., Kaux, J.F., Couffignal, V., Coubard, R., Mélon, P., Cavalier, E., et al. 2011. Identification of cardiac repercussions after intense and prolonged concentric isokinetic exercise in young sedentary people. Eur. J. Appl. Physiol. 111(12): 29973005.

Malinow, MR; Bostom, AG; Krauss, RM. Homocyst(e)ine, Diet, and Cardiovascular Diseases. A Statement for Healthcare Professionals From the Nutrition Committee, American Heart Association. Circulation, 1999; 99:178-182. 
Mangoni, A.A., and Woodman, R.J. 2011. Homocysteine and cardiovascular risk an old foe creeps back. J. Am. Coll. Cardiol. 58: 1034-1035.

Markovitch, D., Tyrrell, R.M., and Thompson D. 2008. Acute-moderate intensity exercise in middle aged men has neither an anti - nor proinflammatory effect. J. Appl. Physiol. 105: 260-265.

Maroto-Sánchez, B., Lopez-Torres, O., Palacios, G., and González-Gross, M. 2016. What do we know about homocysteine andexercise? A review from the literature. Clin. Chem. Lab. Med. 54(10):1561-77.

Moat, S.J. 2008. Plasma total homocysteine: instigator or indicator of cardiovascular disease? Ann. Clin. Biochem. 45: 345-348.

Refsum, H., Ueland, P.M., Nygard, O., and Vollset S.E. 1998. Homocysteine and cardiovascular disease. Annu. Rev. Med. 49: 31-62.

Selhub, J. 1999. Homocysteine metabolism. Annu. Rev. Nutr. 19: 217-246.

Siri, W.E. 1961. Body composition from fluid spaces and density: Analysis of methods. In: Brozek J, Henschel A, editors. Techniques for measuring body composition. Wasington, DC: National Academy of Sciences, National Research Council. 
Sotgia, S., Carru, C., Caria, M.A., Tadolini, B., Deiana, L., and Zinellu, A. 2007. Acute variations in homocysteine levels are related to creatine changes induced by physical activity. Clin. Nutr. 26: 444-449.

Úbeda, N., Reyes, L., González-Medina, A., Alonso-Aperte, E., and Varela-Moreiras, G. 2011. Physiological changes in homocysteine metabolism in pregnancy: a longitudinal study in Spain. Nutrition, 27: 925-930.

Varela-Moreiras, G., Escudero, J.M., and Alonso-Aperte, E. 2007. Homocisteína, vitaminas relacionadas y estilos de vida en personas de edad avanzada: estudio Séneca. Nutr. Hosp. 22: 363-370.

Veeranna, V., Zalawadiya, S.K., Niraj, A., Pradhan, J., Ference, B., Burack, R.C., et al. 2011. Homocysteine and reclassification of cardiovascular disease risk. J. Am. Coll. Cardiol. 58: 1025-1033.

Venta, R., Cruz , E., Valcarcel, G., and Terrados, N. 2009. Plasma vitamins, amino acids, and renal function in postexercise hyperhomocysteinemia. Med. Sci. Sports. Exerc. 41: 1645-1651.

Wald, D.S., Morris, J.K., and Wald, N.J. 2011. Reconciling the evidence on serum homocysteine and ischaemic heart disease: a meta-analysis. PLoS One, 6: e16473.

Weir, J.B. 1949 .New methods for calculating metabolic rate with special reference to protein metabolism. J. Physiol. 109: 1-9. 
Welch, G.N., and Loscalzo, J. 1998. Homocysteine and atherothrombosis. N. Engl. J. Med., 338: 1042-1050.

Zinellu, A., Sotgia, S., Caria, M.A., Tangianu, F., Casu, G., Deiana, L, et al. 2007. Effect of acute exercise on low molecular weight thiols in plasma. Scand. J. Med. Sci. Sports. 17: 452-456. 


\section{$\underline{\text { Tables and figures }}$}

Table 1. Characteristics of the subjects $(n=8)$.

\begin{tabular}{|l|c|c|}
\hline & Mean & SD \\
\hline Height $(\mathrm{m})$ & 1.82 & 0.06 \\
\hline Body mass $(\mathrm{kg})$ & 81.0 & 7.3 \\
\hline BMI $\left(\mathrm{kg} \cdot \mathrm{m}^{-2}\right)$ & 24.5 & 2.5 \\
\hline Sum of $7 \mathrm{skinfolds}(\mathrm{mm})^{a}$ & 100.9 & 39.8 \\
\hline$\% \mathrm{BF}^{b}$ & 13.4 & 5.9 \\
\hline $\mathrm{VO}_{2 \text { peak }}\left(\mathrm{ml} \cdot \mathrm{kg}^{-1} \cdot \mathrm{min}^{-1}\right)$ & 37.4 & 5.9 \\
\hline
\end{tabular}

${ }^{a}$ Sum of 7 skinfolds: triceps, pectoralis, subscapular, abdominal, mid-axilary,

suprailliac, and thigh. ${ }^{b}$ Body density was calculated by the Jackson and Pollock (1978) equation and \%BF was estimated using the Siri (1961) equation.

SD: standard deviation; \%BF: Percentage of body fat $\mathrm{VO}_{2 \text { peak: }}$ Peak oxygen uptake. 
Table 2. Characteristic kinetic parameters (Area under the curve, AUC, Maximum concentration, Cmax and Time to maximum concentration, Tmax) and differences between points post 0 and pre0 and post 19 and pre4 of tHcy in different types of exercise.

\begin{tabular}{|l|l|l|l|}
\hline Hcy & $50 \mathrm{rpm}$ & $80 \mathrm{rpm}$ & $\mathrm{p}$ \\
\hline AUC $(0-30 \mathrm{~min})$ & $304.6 \pm 83.5$ & $345.7 \pm 107.6$ & n.s. \\
\hline Cmax $(\mu \mathrm{mol} / \mathrm{L})$ & $11.4 \pm 2.7$ & $10.8 \pm 3.2$ & n.s. \\
\hline Tmax (min) & $22.8 \pm 16$ & $13.8 \pm 10,6$ & n.s. \\
\hline Dif (final-pre0) & -1.33 & $-2.80^{*}$ & * $\mathrm{p}<0.05$ vs $50 \mathrm{rpm}$ \\
\hline Dif (post19-basal) & -0.85 & -0.40 & n.s. \\
\hline
\end{tabular}

Data are presented as means and standard deviation 
Table 3. Serum folate and vitamin $B_{12}$ concentration before, during, and after two isocaloric exercise trials at low and high frequencies of contraction $(50 \mathrm{rpm}$ and 80 rpm) in sedentary volunteers $(n=8)$.

\begin{tabular}{|l|l|c|c|c|}
\hline & \multicolumn{2}{|c|}{ Folate (ng/ml) } & \multicolumn{2}{c|}{ Vitamin B12 (pg/ml) } \\
\hline & $50 \mathrm{rpm}$ & $80 \mathrm{rpm}$ & $50 \mathrm{rpm}$ & \\
\hline pre4 & $7.1 \pm 2.8$ & $9.2 \pm 6.3^{*}$ & $437.3 \pm 207.8$ & $429.0 \pm 229.7$ \\
\hline pre0 & $9.5 \pm 3.6^{\mathrm{a}}$ & $10.5 \pm 4.3$ & $433.6 \pm 156.7$ & $367.0 \pm 113.9$ \\
\hline exer10 & $8.9 \pm 1.9$ & $10.1 \pm 3.3$ & $411.0 \pm 189.9$ & $384.0 \pm 166.2$ \\
\hline exer20 & $8.1 \pm 1.3$ & $10.9 \pm 2.8$ & $363.8 \pm 70.8$ & $387.4 \pm 124.4$ \\
\hline exer40 & $8.6 \pm 1.0$ & $10.2 \pm 2.8$ & $342.8 \pm 58.5$ & $388.4 \pm 190.0$ \\
\hline exer50 & $8.2 \pm 2.4$ & & $431.3 \pm 210.4$ & \\
\hline exer60 & $8.2 \pm 1.3$ & & & \\
\hline post0 & $10.3 \pm 2.6$ & $16.8 \pm 6.1^{\mathrm{b}}$ & $441.2 \pm 183.7$ & $630.4 \pm 299.3^{\mathrm{bt}}$ \\
\hline post19 & $9.5 \pm 3.3$ & $19.5 \pm 7.0^{* \mathrm{c}}$ & $392.8 \pm 141.5^{\mathrm{d}}$ & $801.1 \pm 249.9^{* \mathrm{cde}}$ \\
\hline
\end{tabular}

Data are presented as means and standard deviation. Significant differences $(\mathrm{p}<0.05)$ from: *between the two trials in the same sampling point; ${ }^{a}$ pre 0 vs. pre4; ${ }^{b}$ post 0 vs.

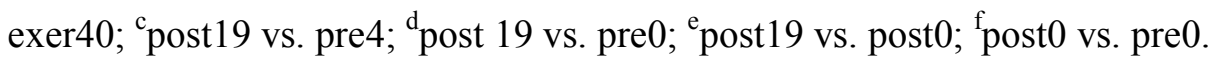

Pre4: blood sample 4 hours before exercise; pre0: blood sample immediately before exercise; exer40: blood sample 40 minutes during exercise; post0: blood sample immediately after exercise; post19: blood sample 19 hours after exercise. 
Table 4. Characteristic kinetic parameters (Area under the curve, AUC, Maximum concentration, Cmax and Time to maximum concentration, Tmax) of Folate in different types of exercise.

\begin{tabular}{|l|c|c|l|l|c|c|}
\hline & \multicolumn{2}{|c|}{ Folate } & \multicolumn{3}{c|}{ Vitamin B12 } & \\
\hline & $50 \mathrm{rpm}$ & $80 \mathrm{rpm}$ & $\mathrm{p}$ & $50 \mathrm{rpm}$ & $80 \mathrm{rpm}$ & $\mathrm{p}$ \\
\hline AUC $(0-$ & $295.1 \pm 90.6$ & $296.9 \pm 88.2$ & n.s. & $118020 \pm$ & $11780 \pm 4075$ & n.s. \\
$30 \mathrm{~min})$ & & & & 3043 & & \\
\hline Cmax & $11.6 \pm 4.3$ & $20.2 \pm 9.7^{*}$ & ${ }^{*} \mathrm{p}<0.05 \mathrm{vs}$ & $468.7 \pm 198.6$ & $640.0 \pm 288.5$ & n.s. \\
$(\mathrm{ng} / \mathrm{mL})$ & & & $50 \mathrm{rpm}$ & & & \\
\hline Tmax & $20.2 \pm 16.3$ & $51.4 \pm 22.7^{*}$ & ${ }^{*} \mathrm{p}<0.05 \mathrm{vs}$ & $37.1 \pm 24.3$ & $50.0 \pm 19.1$ & n.s. \\
$(\min )$ & & & $50 \mathrm{rpm}$ & & & \\
\hline
\end{tabular}

Data are presented as means and standard deviation 
Table 5. Nutritional intake of volunteers $(n=8)$ during the experimental trial days, target energy intake, Recommended Dietary Allowances (RDA) and Acceptable Macronutrient Distribution Range (AMDR).

\begin{tabular}{|l|c|c|}
\hline & Intake & Intake targets $^{\mathrm{a}}$ \\
\hline Energy $(\mathrm{kcal})$ & $2869 \pm 171$ & 3123 \\
\hline Carbohydrates $(\% \mathrm{E})$ & $67.3 \pm 2.9$ & $45-65$ \\
\hline Lipids $(\% \mathrm{E})$ & $19.1 \pm 3.5$ & $20-35$ \\
\hline Proteins $(\% \mathrm{E})$ & $13.6 \pm 13.6$ & $10-35$ \\
\hline Folate $(\mu \mathrm{g})$ & $646.0(177.0-683.0)$ & 300 \\
\hline Vitamin $\mathrm{B}_{12}(\mu \mathrm{g})$ & $22.7(3.2-25.7)$ & 1.4 \\
\hline Vitamin $\mathrm{B}_{6}(\mathrm{mg})$ & $6.2(1.8-6.5)$ & 1.5 \\
\hline
\end{tabular}

Data are presented as Median and standard deviation or Median (Interquartile range).

${ }^{a}$ Intake targets: For Energy intake the energy requirements were calculated using the Harris-Benedict equation, multiplied by a physical activity factor (1.4), and with 400 kcal added to account for the energy expenditure during the exercise trial. For Macronutrients and vitamins, the Acceptable Macronutrient Distribution Range (AMDR) and the Recommended Dietary Allowances (RDA) were used, respectively.

$\%$ E: percent of energy intake 


\section{Figure 1. Experimental design}

\section{Figure 2. Serum homocysteine kinetics at two exercise trials.}

Solid lines and dots in low cycle cadence (50 rpm) exercise and dashed line and triangles in high cycle cadence $(80 \mathrm{rpm})$ exercise. Data are presented as means and standard deviation. No statistically significant differences were observed between values obtained at the same sampling points in both trials.*Significant differences $(\mathrm{p}<0.05)$ in high cycle cadence $(80 \mathrm{rpm})$ exercise between pre 0 vs. pre4, post19. ${ }^{\&}$ Significant differences $(\mathrm{p}<0.05)$ in low cycle cadence $(50 \mathrm{rpm})$ exercise between pre4 vs. pre 0 and post 19 ; pre 0 vs. exer20 and post 19 ; post 0 vs. post 19.

Pre4: blood sample 4 hours before exercise; pre0: blood sample immediately before exercise; exer20: blood sample 20 minutes during exercise; post0: blood sample immediately after exercise; post19: blood sample 19 hours after exercise. 


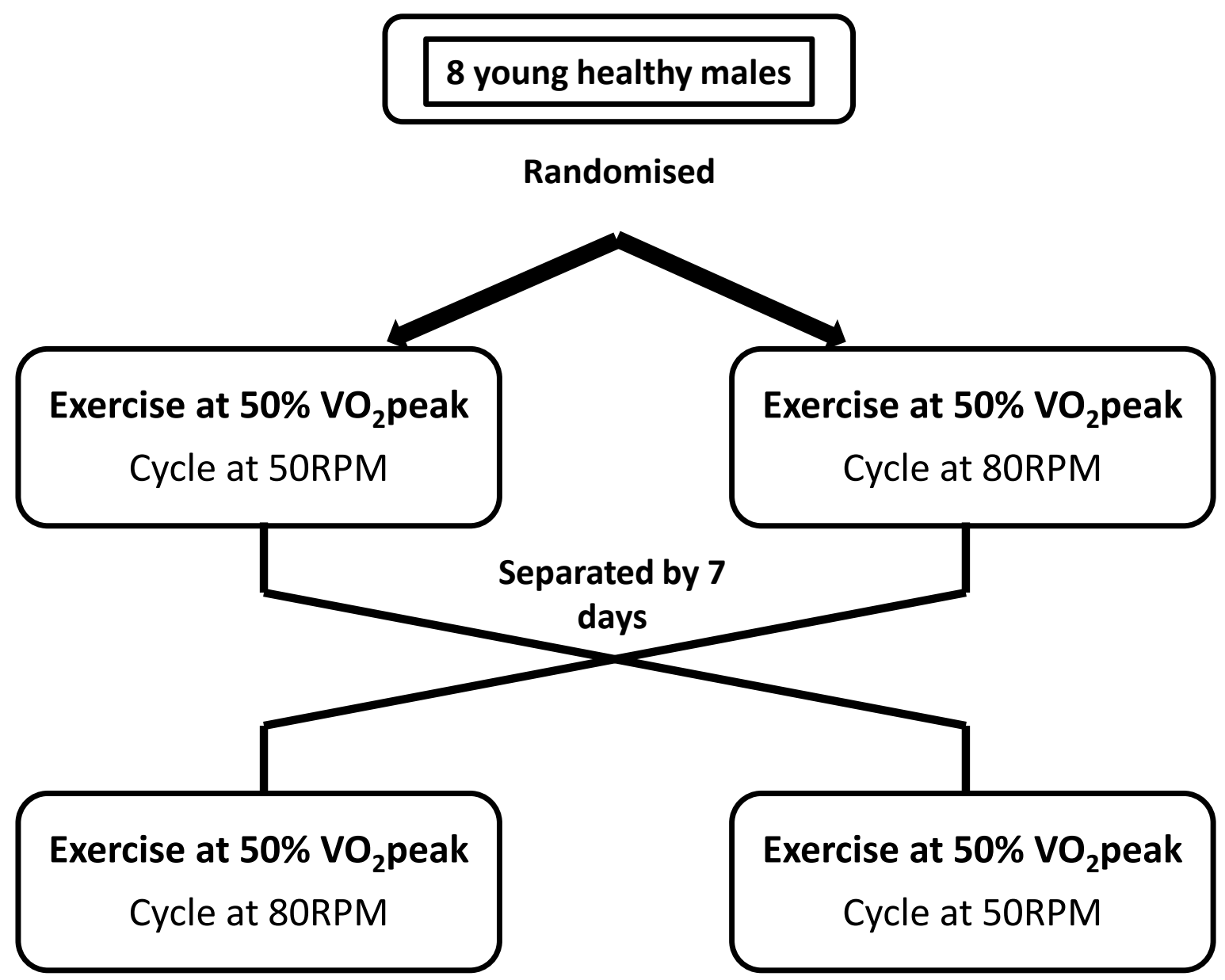




\section{HCY evolution of the means}

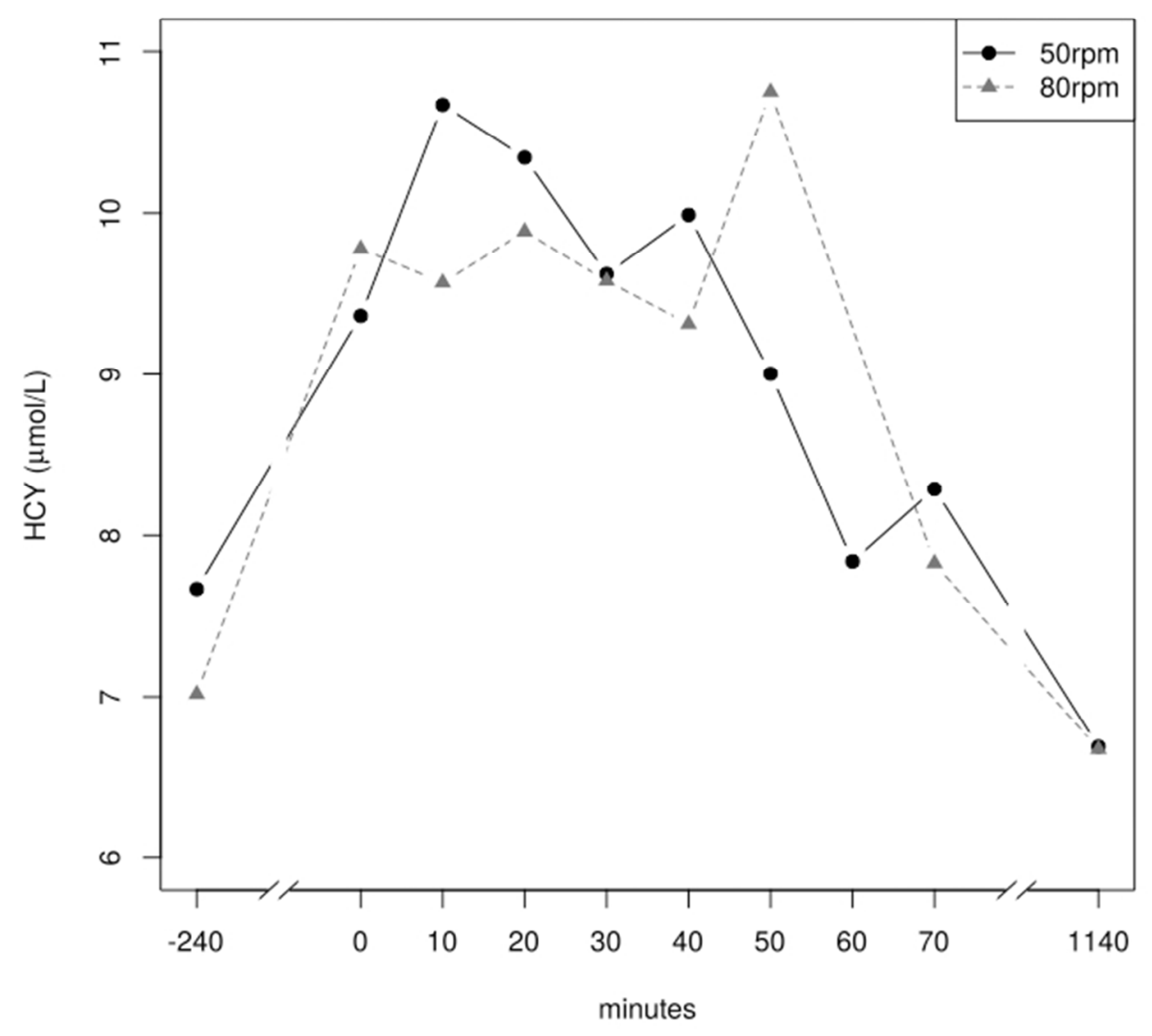

$56 \times 56 \mathrm{~mm}(300 \times 300$ DPI $)$ 